\title{
In design we trust: dealing with the innovation imperative
}

\author{
Henning Berthold, Shiona Chillas, Barbara Townley
}

\begin{tabular}{|l|l|}
\hline Date of deposit & [16 11 2016] \\
\hline Document version & Original submitted pre-edited manuscript \\
\hline Access rights & $\begin{array}{l}\text { This draft chapter that has been published by Edward Elgar } \\
\text { Publishing in International Perspectives on Business Innovation } \\
\text { and Disruption in Design edited by (Robert Defillippi, Alison } \\
\text { Rieple and Patrik Wikstrom) published in 2016'. } \\
\text { [Available on Elgaronline http://www.elgaronline.com/ DOI } \\
10.4337 / 9781784716646]\end{array}$ \\
\hline $\begin{array}{l}\text { Citation for } \\
\text { published version }\end{array}$ & $\begin{array}{l}\text { Berthold, HA, Chillas, SA \& Townley, B 2016, In design we trust: } \\
\text { dealing with the innovation imperative. in R DeFillippi, A Rieple \& } \\
\text { P Wikstrom (eds), International Perspectives on Business } \\
\text { Innovation and Disruption in Design. Edward Elgar, Cheltenham, } \\
\text { pp. 276-295. }\end{array}$ \\
\hline $\begin{array}{l}\text { Link to published } \\
\text { version }\end{array}$ & \begin{tabular}{l} 
http://dx.doi.org/10.4337/9781784716646.00023 \\
\hline
\end{tabular}
\end{tabular}

Full metadata for this item is available in St Andrews Research

Repository at: https://research-repository.st-andrews.ac.uk/

\section{St Andrews Research Repository}


In Design We Trust: Dealing with the Innovation Imperative

Book Chapter for 'Business Innovation and Disruption by Design'

Final Draft

Henning Berthold*, Shiona Chillas and Barbara Townley

School of Management

University of St Andrews

St Andrews, Fife, KY16 8HZ

Scotland, UK

* Corresponding author.

Email-address: hab27@st-andrews.ac.uk 


\begin{abstract}
Following an initiative intended to stimulate new business ventures, this chapter discusses design as an integrative discipline of understanding, helping to overcome disciplinary divides that characterise the development of innovative goods. It illustrates how, for design to function, locally established epistemic structures allow for people with different frames of reference and exploratory approaches to settle on a shared path of inquiry. In this sense, design fulfils a brokering function that helps to align different 'ways of knowing' along the processes of collaborative exploration. In promoting testing and reasoning along the often winding path from problem finding to problem solving, from the conception of ideas to their realisation, design supports activities of learning that help with the inherent uncertainties that characterise the development of innovative goods. Within such a process, designers, embedded in a network of mutually influencing actors, act as capable, multilingual ambassadors on the ground, able to fulfil an integrative and translational role.
\end{abstract}




\section{Introduction}

As a process of inquiry, centred around the generation of ideas and activated to solve problems of economic and - increasingly - societal importance, design has become recognised as a key function of innovation and international competitiveness (Andrews \& Criscuolo 2013). This notwithstanding, its utilisation as a structural ingredient in the developmental processes of new products, services, processes and systems remains underexploited (UK Department for Business, Innovation \& Skills 2014). Rather than trying to understand the causes of resistance, however, this chapter seeks to understand how design plays out and is harnessed in the process of innovation and entrepreneurial venturing and functions as a value creation mechanism (see e.g. Thomson \& Koskinen 2012; Johansson \& Woodilla 2012; Junginger 2012, 2009). The chapter investigates its enabling capacities whilst challenging the notion of the 'omnipotent designer' and being sceptical of the introduction of design as an unexpected power, a deus ex machina (cf. Walters 2011). Instead, it examines what it means for designers to act in their 'normal capacity' and how they might intervene in the ideation to monetisation process. It does so by using empirical material from a Scottish innovation initiative that aims to investigate the strategic capacity of design in the context of a novel innovation mechanism. In doing so, it aims to help the development of a more integrated innovation vocabulary and cumulative body of knowledge on design-driven (business) innovation as called for by Johansson and Woodilla (2009).

The capacity of a nation to create, innovate and move beyond its current state is widely recognised as being vital to its economic success and social prosperity. This is particularly true for the advanced economies operating closely at the forefront of technological development, whose sustained success is more and more dependent on 'improvements in 
multi-factor productivity' (OECD 2012). The rise of the information society in the last quarter of the twentieth century, has led to the heightened importance of knowledge-based capital (KBC) as a key driver of innovation-based growth. According to the OECD (2012), firms in some of its member countries, such as Sweden, the United States and the United Kingdom, now spend as much or even more on non-physical assets as on those with physical embodiment. Such shifts in resource allocation are indicative of substantial economic restructuring and institutional transformation. Emerging economies such as India and Brazil are contributing to this trend, claiming an increasing share of global investment in innovation and addressing the stimulation of $\mathrm{KBC}$ investment as an issue of central political concern (OECD 2012). It is precisely the national need for entrepreneurial activity and growth in innovation that has formed the rationale for the design-led initiative considered in this chapter, as over the past three decades the Scottish economy has consistently underperformed in terms of growth relative to both the UK and other small European countries. Factors seen as particularly problematic in light of Scotland's poor productivity performance are the low levels of business R\&D, weak links between the country's research base and business innovation as well as the limited number of (high-tech) new venture formations (The Scottish Government 2007).

The aim of the initiative therefore was twofold: to infuse design into the process of business innovation on the one hand, and purposefully integrate university research and industry knowledge on the other. The innovation process, labelled Chiasma, rests upon a variation of the research-focused IDEAS Factory Sandpit-model conceived by the UK Engineering and Physical Sciences Research Council (2012). The Sandpit, as described by the EPSRC (2012), is a mentored, residential interactive workshop, engaging a multidisciplinary group of researchers and potential research beneficiaries (20-30 people in total) with the concept of 
'creative, intellectual play' to elicit new thinking around specific research problems and translate its outcomes into 'ground-breaking proposals'. The principal idea of the Sandpit is to 'inject innovation into contemporary science' (EPSRC 2012). Focusing on the workshop model employed by the initiative introduced here, we aim to provide insight into the workings of this newly adopted innovation mechanism and the potentially catalytic function of design. The mechanism is to serve as an engine for design-infused knowledge exchange that promotes thinking around complex issues of societal importance and the creation of new opportunities for commercialisation across sectors traditionally distant to design (here, wellbeing, food, sport, rural economies and ICT). Examined is the extent to which design may serve as a strategic tool and enabling capacity in the development and realisation of marketable ideas, emphasising the role of design as a medium of reflection on important issues and mechanism to try and explore ideas beyond considerations of the aesthetic. Design is thus seen not as a service, a discretionary item or add-on, but a force that transforms organisational thinking and acting and sediments as an integral component of management practice.

\section{Design thinking}

There are these two young fish swimming along, and they happen to meet an older fish swimming the other way, who nods at them and says, 'Morning, boys, how's the water?' And the two young fish swim on for a bit, and then eventually one of them looks over at the other and goes,

'What the hell is water?' 
Wallace's (2009, p. 10) story is to serve as a reminder that 'the most obvious, ubiquitous, important realities are often the ones that are the hardest to see and talk about.' In as far as the objects we surround ourselves with, the products we use, the services we demand, the processes we rely on, the environments we are interacting with, are the products of human engagement, intellectual endeavour and creativity, design is everywhere, or in Wallace's terms: ubiquitous. In its formative and transactional capacity, design shapes the human/environment relationship and how we come to see it. Immanent in design is an optimistic view of man's ability to actively deal with an ever-changing environment and the challenges it presents. In enabling us to conceive and give form to novel solutions that may help to resolve doubt and settle an otherwise indeterminate situation, design has instrumental character. More than just helping to solve problems and recalibrate the relationship between individuals and their environment, however, design is often held to be a matter of '[grasping and] realising new possibilities and discovering our reactions to it' (Jones 1992, p. xxvii). Design thus is transformative in terms of its ontological implications, manipulating the environments we engage with, provoking new ways of seeing, thinking and acting. It is such ability to digest complex issues and envision new realities that arguably has paved the way for design to enter the economy on a broader scale.

The term that is commonly being used in this context is 'design thinking'. A concept that resonates with Herbert Simon's (1969 [1996], p. 114) notion of design as a discipline of thinking that allows us to determine 'how things ought to be' as opposed to 'what is'. Design thinking has gained prominence over the past years with the adoption of the term by management scholars and those seeking to promulgate the value of design (thinking) for 
innovation. Particularly noteworthy in this context is the work undertaken by Stanford's d.School and authors such as Tim Brown $(2009,2008)$, CEO and president of the worldrenown design agency IDEO, who have distinctly shaped the design thinking discourse in management and helped the term's popularisation across various sectors (public and private) and trades. In fact, much of the public presentation of design thinking 'is tied to [this] one design [firm]' (Kimbell 2011, p. 289), rendering the discipline strikingly self-referential. Brown $(2008$, p. 1) promotes a view of design thinking as an empathic approach to problem solving, 'a methodology that imbues the full spectrum of innovation activities with a humancentered design ethos'. Despite variations in the conceptualisation of design thinking (Hassi \& Laakso 2011), user-centrism and the consideration of human values have emerged as defining characteristics. That is, the concept is often associated with a view of innovation that reorients aspects of technological feasibility, commercial viability and practical usability/desirability, giving precedence to the 'observation and discovery of $[\ldots]$ human needs' (Gruber et al. 2015, p. 1; Stanford University Institute of Design 2015). This view is not uncontested if we consider, for instance, Verganti's (2009) scepticism towards the user or customer as a source of innovation that may transcend existing meanings and push the boundaries of how we see and understand the 'artificial world' (Cross 1982, p. 222). Rather he, Verganti, envisages a kind of 'design-driven innovation' (as an alternative strategy to incremental and radical innovation) that looks beyond immediate user insight to observations from a diverse network of agents (artists, designers, researchers, suppliers and strategic partners) or 'interpreters', as he calls them, operating close to or within the specific field of exploration and able to identify and/or anticipate shifts in the sociocultural and technological context and associated semantic frames. Notwithstanding this, 'designerly' ways of thinking and acting have been widely heralded as a capacity to confront 'wicked problems' (Rittel \& 
Webber 1973), problems that are ill-defined and highly complex thereby opening up new pathways to innovation.

Core to such ability is a particular approach to inquiry that is driven, apart from empathy, by values of 'practicality, ingenuity, and a concern for appropriateness' (Cross 1982, p. 222); an approach that emphasises 'modelling, pattern-formation [and] synthesis' (ibid.) and translates into a process that deviates from the linear, analytical approach often associated with early design theory, scientific methods and conventional management practice. Design approaches have evolved into a highly iterative process, moving from the observation of specific human contexts (discovery phase), to the framing of a problem (definition phase), to the development of possible solutions (ideation phase), to the implementation and testing of a selected course of action (delivery phase) (Gruber et al. 2015). It is the way designers generate knowledge (through iterative processes of inquiry) and turn such knowledge into practical solutions that has made design become recognised as valuable tool for innovation both within the commercial realm and beyond. The portfolio of work ranges from crafting new products, to improving public services, to shaping interactions, to giving form to complex systems. It is worth noting, though, that despite the prominence of the concept of design thinking, 'some industry observers are beginning to question its most fundamental assumptions' (Kimbell 2011, p. 286), i.e., assumptions about the appropriability of design principles, practices and knowledge within vastly different contexts.

The spreading of design thinking followed in the wake of a gradual expansion of design services in the twentieth century from a once 'discretionary input' and 'servile activity' (Green et al. 2013; Buchanan 2001), to an integral function in the exploration and exploitation of new value creation mechanisms. The development is captured in Buchanan's 
(1992, pp. 9-10) 'four orders [or places] of design', which demarcate the field as follows:

(first order) the design of 'symbolic and visual communications', (second order) the design of 'material objects', (third order) the design of 'activities and organised services' and, ultimately, (fourth order) the design of 'complex systems or environments for living, working, playing, and learning', i.e., design no longer restricted to being a specialised practice focused on the creation of form and beauty (aesthetics) but as a generalised tool for strategic intervention (Verganti 2009). We explore the roles that design potentially plays in such strategic intervention through an exploration of its function in relation to three identified sub-processes of innovation: the production of knowledge; the transformation of knowledge into working artefacts, and the continuous matching of the latter to market needs and demands (Pavitt 2005).

\section{Inquiring into the field of design}

The initiative reported on here is delivered by a national consortium of both academic and non-academic organisations. The five areas of focus (wellbeing, food, sport, rural economies and ICT) were derived from Scottish policy documents (The Scottish Government 2007; 2011) and are to be understood as operational fields of particular social and economic importance. They not only reflect specific terrains of economic activity spanning standard industrial classifications (in the case of the food sector, for instance, the initiative engages with various audiences from food production to support services) but also business domains scarcely experienced in the strategic utilisation of design.

Central to the initiative are the mentored, residential innovation workshops. Shaped through design methodologies, these workshops are set to engage with a selection of themes and 
issues previously identified through scoping work undertaken by members of the academic consortium in dialogue with a network of experts or, to use Verganti's (2009) term, 'interpreters', i.e., people with a thorough understanding of their specific sectors and an ability to decipher emerging trends. The scoping phase not only serves to learn about issues from those at the forefront of debate but also to generate interest and encourage participation in the subsequent workshops. Brought together are an eclectic group of people that fall into the categories of entrepreneurs, academics, designers and those not matching any of those groups (wildcards). In the context of the workshops and beyond, designers - for the purpose of the project loosely defined as those that make a living of their craft - are ascribed (usually covertly) a central role in the development of ideas, the creation of concepts and their translation into prototypes. They are expected to assume a particular responsibility in working with people to generate new ideas and guiding them along the process of actualisation. Nurturing the exchange of knowledge and experience through facilitation and the utilisation of design thinking and methods, the initiative seeks to burrow into the formation of transformative solutions. The aspiration is for new ideas for each of the sectors identified. In order to ensure their development to a marketable stage, prototyping is supported with up to $£ 20,000$ and a range of support services. Innovation thus lies not only in the development of new products, services and/or processes but equally the creation of new ventures as their commercial vehicles.

With the purpose of tracing the role of design and its enabling capacity along the ideation to monetisation process, we conducted research from idea generation (centred around the Sandpit-inspired, mentored innovation workshops), to funding panels, prototyping and business design stages, and where possible, business development. In order to uncover the strategic potential of design, however, the focus of this chapter, specifically, is the material 
gathered during the workshops and post funding. In all, 15 business have been followed, i.e., all those which were granted funding from the funding panel to take their ideas forward to the business initiation stage.

As members of the academic consortium, we need to acknowledge and specify our involvement with the workshops we later went to study. Although following the process, we were not actively involved in the realisation of the workshops, nor the management of the post-workshop stages. Instead, our primary task was to collect data. However, there is an inevitable empirical bias in the study reported on here towards a sympathetic view of design, in that, despite the initiatives' engagement with sectors not traditionally associated with design, in response to the call for participation, participants shared a general curiosity, if not awareness about it. The chapter therefore avoids the use of apriori understandings of design and interrogates the empirical material to illuminate the different forms of engagement with design, its utilisation as an engine for creativity and innovation, and the challenges associated with this.

\section{Views from the field}

Design in the context of the present initiative might be grasped, perhaps surprisingly, as something of an absent presence, in that, although written into the architecture of the workshops (Chiasma) and entangled in the fabric of the process that extends beyond the boundaries of the event itself, it quickly fades into the background. Confronted with the task to develop novel solutions to problems of societal importance - ranging from self-managing type-2 diabetes to enabling participation in physical activity for special need groups, to incentivising living and working in rural economies, to exploiting current and emerging 
technologies in the information and education sectors - workshop participants are taken through a well-choreographed and closely timed process of collective sense-making that involves deliberation over the issues at hand, setting boundaries of relevance, investigating the problem and ideating possible solutions. The process engages the participants with a varying selection of pre-designed methods and tools (such as empathy maps, persona templates, challenge cards, idea generators, business model designs etc.), processes and structures (as imposed by the rhythm of the two and half day event and repetitive sequences of divergent/convergent thinking), that serve to encourage playful attendance to the task at hand. Design is therefore engaged with 'in action' and not in an abstract state. Indeed, participants unfamiliar with design are rather unaware of what might constitute a design process or, more specifically, a design-led process of idea formation as is commented here: 'Not coming from a design background, I would not know the conventional design process for how an idea is developed' [Greg, Entrepreneur, Rural Economies]. In the absence of an interpretative framework, the workings of design are often found difficult to grasp, creating a desire amongst non-designers to learn more about it, both in the context of the workshop and beyond. Designers, embedded in the process and briefed prior to the event to perform design on a technical as well as strategic level, rarely work to remedy such confusion by explicating what they do. Instead, they are typically observed articulating design through practice (capturing insights, organising/visualising ideas, mapping experiences, developing narratives etc.), allowing participants to have an experience of design and recognise its function as a 'situated, local accomplishment' (Kimbell 2012, p. 129) as is indicated by one of the designers:

I can remember being at the [Rural Economies Chiasma] and saying we should really try and personify stuff. And everyone's like, 'Yeah, that's quite a good idea, let's do it.' 
And you don't really need to explain it in any way, it's just like this is what we're trying to do. [Paula, Designer, Wellbeing]

As design is articulated through practice, participants learn about its principles (closely observing human needs) and methods (by means of 'personify[ing] stuff') by taking part in the action. The workshops encapsulate a concept of design that emphasises its integral role in the process and as such is experienced in the action-present. To the extent that participants are addressed as a collective rather than representatives of specific groups (designers, academics, entrepreneurs, other individuals), the event creates (relative) parity between the actors and shared agency in the process. That is, designers are 'de-centred' (Kimbell 2012) rather than noticeably elevated. Although it should be noted that people were asked to wear colour-coded lanyards to make them identifiable as belonging to one of the aforementioned groups for research purposes. The colour codes, however, often paled into insignificance as the process went on. The expressed aim of the initiative was to activate design in a strategic capacity. That is, design was to serve as a vehicle to achieve specific (locally defined) endsin-view by integrating designers in each project emerging from the event and utilising their skills and knowledge. We now turn to some of the views of design that were formed in the midst of action.

Design as an exploratory practice: The production of knowledge

Chiasma, i.e., the process from scoping a problematic situation to the actualisation of ideas, centres around the sharing and collaborative production of knowledge. Emphasised is a notion of design as an integrative practice, bringing together expertise from different disciplines, principally the arts (designers), (social) sciences (academics) and business 
(entrepreneurs). The composition of the workshops is central to the participant's experience and often an important reason for them to attend the event in the first place.

The Chiasma 'space' is one of coordinated action that is used to activate different dimensions of design, namely, design as a guiding principle (or philosophy), a process and a set of methods. These elements combined may be understood as a design methodology, a holistic approach to design that is shaping the atmosphere of the workshops, the structure of the process, the performances of the designers, the interactions between participants, the use of the materials provided and, ultimately, the path of inquiry and formation of ideas. Inquiries pursued during the workshops, channelled through the process, do not unfold in a 'cultural' vacuum, however. The intellectual endeavours are grounded in a set of contextually defined principles and rules of engagement. These organising frames are enacted through a variety of materials including the call for participation and attached rules of engagement (to be signed prior to the event), informational material on the initiative's website, introductory texts provided upon the arrival and not least the verbal instructions uttered by the facilitators throughout the event. Their structuring character is captured in one of the participant's accounts:

It was made clear at the start to just let it all out, just don't worry about that, don't shoot anyone down. And because that was the environment then, people opened up more and I don't think anyone was holding back. I certainly wasn't, and the group I worked in. I don't think so either. [Ben, Entrepreneur, Food]

These framing elements work to create an environment, in which participants feel comfortable and encouraged to explore and articulate unorthodox ideas. The early stages of 
inquiry in particular were designed to ensure openness and facilitate the 'externalisation' of relevant knowledge that people may bring to the event and that may help to grasp the problematic situation. 'People', as it is stated in one of the calls, are 'expected to break down barriers and build up thoughts on how the identified challenges can be addressed'. Such framing not only serves to create a particular atmosphere but also manage people's expectations and nurture what might be called an exploratory attitude of mind; an attitude defined by alertness, curiosity and openness to experimentation. It is also through such texts that participants learn about 'how we think of design', to use one of the facilitators' words, namely as something that ought to be 'injected[ed] into all sorts of use-cases' and brought to fruition by incorporating designerly practices into the process. Such directives do not provide a static set of rules, but are principles engaged with and operationalised in practice.

Ice-breaker activities allow people to get to know each other and gradually enter a lighthearted, yet meaningful exchange of thoughts, as for example, an interactive format that requires participants to reveal their attitude towards certain, contextually relevant, statements by taking position in one of four predefined spaces (strongly agree - agree - disagree strongly disagree). This playful approach often leads to a lively debate as participants are invited to explain their views to the rest of the group and in so doing share insights, identify issues and highlight subjects to be further investigated. Through this, participants are developing a sense of the problem space and start building a common understanding of the subject in scrutiny. The purpose of such interventions is to 'open up thinking', as one facilitator suggested, promoting intellectual expansion or what is described in design thinking language as 'divergence' (see Brown 2009), i.e., the creation of choices as opposed to the making of choices ('convergence'). Divergence and convergence are antagonistic steps repeated throughout the process, leading to a gradual refinement of ideas as more information 
becomes available. The creation of choice is premised on the externalisation of knowledge and the recognition of what one facilitator described as 'the enormous expertise in the room'. The motivation is 'to get our knowledge out' and build what might be understood as a shared 'knowledge library'; a collection of informational material ranging from new technologies to emerging business models, from inspiring people to valuable contacts, from potential funding opportunities to important policies. The material circulates and evolves through the conversations participants engage in, as they try to make sense of the problematic situation and start extracting themes and ideas as to how to address this. Ideation is supported through tools such as rapid idea generators that work to encourage lateral thinking and experimentation with established ideas. Groups form and reform around these ideas, shaping them and the underlying debates. As groups prepare to present their ideas to their fellow participants for feedback, their thinking is to be organised - even if only temporarily - into something of coherent whole. It is this process of '[tying] together the disparate voices to some sort of coherency' [Gary, Designer, ICT] that some designers associate with their role:

I guess, kind of bringing together everything and listening and understanding the needs of different parties. But then being able to bring it all into one coherent thing, so that you know where the compromises are made and how much that will last. [ibid.]

The purposeful integration and development of knowledge is effected through the guided use of exploratory tools (such as context maps, future maps, empathy maps, persona templates, value canvases, business models, $5 \mathrm{Ws}$, presentation material etc.). Such tools, including the emerging ideas captured in various forms (such as post-its curated on large pieces of paper), work as 'boundary objects' (Sapsed \& Salter 2004) that enable dialogue and the 'integration of knowledge' (Buchanan 2001, p. 7) through the artefact. The artefacts, as one of the 
designers described it, form 'a shared reference point for people to talk through' [Paula, Designer, Wellbeing].

Through the iteration of key tasks (such as developing ideas), employing task-specific tools and moving people around (allowing for the discussion of emerging themes and ideas within different group constellations), participants are prevented from settling on ideas too early. Ideas are subject to open examination, with working groups having to present their ideas to the plenary. In order maximise input from the other participants and democratise the evaluative process during the early stages of idea formation, feedback is provided by everyone involved in the process (including facilitators). Unless an idea is dropped or parked, the collected feedback is then used to rework and further scrutinise the proposition. It is this stripped-down, iterative process of conceiving and testing ideas that leaves one designer characterising design as 'just a thought process' [Tom, Designer, Food]:

It's just...you know, you look at different ways of doing something and you try...yeah, you just test ideas. [ibid.]

Design, as the comment makes clear, derives its meaning as well as its value and legitimacy from the courses it defines in action. 'It is very subjective' [Anne, Designer, Wellbeing], and as, such contingent on the situation within which design is activated. How the teams embark on the process of concretising their ideas and turning their individual mental images into something of an integrated product is investigated in the following section.

The transformation of knowledge into artefacts 
Knowledge to identify focal areas, inform possible courses of action, test their appeal and settle on a solution is a non-linear process, often involving a messy back and forth movement between problem definition, idea formation and experimentation. As new insights become available, understanding improves of the problem itself and possible solutions. The translation of such solutions or ideas into artefactual representations, the manifestation of ideas, is a common association with design amongst participants. It is on this level that a number of participants have encountered design before:

[I]n order to have my ideas made manifest, if you like, I work with designers and I'm very, very comfortable and used to working with designers, who will produce either a digital film for me that goes online or a piece of print or graphics for an interpretative panel. So I'm used to commissioning stuff. [Claire, ICT, Entrepreneur]

The process of translating ideas into something artefactual demanded great collaborative effort between designers and non-designers. Collaboration across disciplinary boundaries requires a degree of learning about the other areas of expertise to be able to effectively work together, not for people to become experts in and of their own right but for the development of shared understandings. Such learning is often prompted by moments of confusion, involves interrogation, explanation, takes time and slows down what otherwise might be a straightforward process, as in this account of developing a computer game, by one of the designers:

Usually, I am working with other game designers and you can go really fast, whereas [working with non-gamers] was slowing us down. But on the other hand, I guess, it made me think it through. [X] was saying, 'Right what is the first thing that you are 
going to see on the screen? What would you be doing?' And so coming down to that meant that we had to earth it a wee bit which was very useful. [Nathan, Sport, Designer]

Such questions work to make explicit some of the mental images people might construct about the solution, test their assumptions, their thinking, their language and facilitate the exchange as well as integration of what Schön (1992) defined as individual 'design worlds', i.e., particular problem-solving approaches. The disruption of routinized work flows and need for clarification not only works to slow down the process but also prevents groups from 'get[ting] into detailed design too early' [Dave, Entrepreneur, Wellbeing], leaving room for continued exploration and the manifestation of ideas. Whilst some responded impatiently, others deliberately abstained from rushing things and transforming ideas into a solid state:

I mean, one of the things we have been careful to try not to do is to get into detail design too early. And I think you can do that, or that can be done, and it is recognised by the people who have probably more business experience than pure design experience. [ibid.]

It is worth emphasising that such carefully paced approach to problem solving is seen as something of an adjusted form of designing, integrating business and design logics within the process of exploration. The importance of research and dedicating time to the identification of possible courses of action finds further articulation in what one designer describes as the difference between 'outcomes' and 'outputs': 
What I would say about the design approach - I always panic about this word solution - is probably that often it helps us to focus more on outcomes than on outputs. So the design approach is 'What is the outcome we want here?', the outcome is, for example, 'better self-management', and then working back from there; as opposed to, perhaps, focusing on a solution that has limited application. So, I think, the fact that we took a very broad scoping approach to what are the outcomes and then design back from there, really, to what would help us achieve these outcomes. [Lisa, Designer, Wellbeing]

Part of the process requires participants to embrace uncertainty - something some participants noticeably struggle with - and become comfortable with the concept of trial and error learning, moving back and forth between stages of development and thus using the process in such a way that it yields what those involved might consider as the most satisfactory solution. The learning typically involves interaction with a few carefully selected individuals or groups (principally those thought to benefit from a proposed solution and those considered vital to its success in as far as they would contribute critical resources otherwise missing such as knowledge, technology, money etc.) and is supported by means of early prototyping, allowing the team and other actors involved to understand and 'demonstrate what it [a solution] would look like' [Gary, Designer, ICT].

[The task is to develop], I guess, not just the visuals but some sort of prototype so that you can clearly demonstrate what it would look like. I mean, prototype in like a very early prototype, a paper prototype, for instance, so you understand when you engage with different menus [for a game], for instance. [ibid.] 
Translating ideas into artefacts demands being concerned with form in a holistic way, considering the interconnectedness between functional/technical, aesthetic and directional/commercial aspects or indeed between the disciplines of art, science and business. Rather than pursuing a 'literal' translation of the ideas into a 'product' or 'thing', the evolving artefact is to capture its identity (as a brand) and how this ought to be enacted:

I think, having designers there to be able to say 'No, this is not really the key aspect of it [the solution], this is perhaps something that we might do later.' Having that understanding is important. Also, to be able to turn it not just into a product but turn it into a brand. You know, what's the value that you're trying to communicate towards the public, towards a potential customer base? And what then are ultimately the routes to that market like? [...] I think the designers at each stage have been quite influential in determining that. [ibid.]

Artefacts as early manifestations of entrepreneurial ideas are 'living things' and as such subject to continuous examination and alteration. We therefore are now to turn to the final sub-process of innovation in order to illuminate some of those activities.

The matching of artefacts to specific demands and needs

As elaborated earlier, the workshops are placed within a specific thematic context. That is, participants are confronted with a set of issues to contemplate and respond to by identifying specific demands and/or needs. As the issues are interpreted and reinterpreted throughout the process and in conversation with a growing number of stakeholders (advisors, collaborators, partners, potential funders/investors etc.), the thrust and composition of ideas and working 
prototypes may alter with the level of understanding of the target audience and their specific demands and needs. In order to get closer to the potential buyers or users, the emerging new venturers would commonly try and enter a dialogue with a rather diverse sample group, allowing themselves to be surprised and leaving room for further calibration. Dialogues were organised in different formats, ranging from informal conversations, to interviews, to focus groups, to physical pilots. How such conversations may alter the course of action is documented in one participant's reflection on a focus group that was employed to invite comments on his prototype and the business proposition underlying it. The project concerned had emerged from the second Food Chiasma and revolved around the development of a small-size smart device for cultivating food plants within the home and office environment. The focus group, specifically, was designed to inquire into people's lifestyle (activities); understand their attitudes towards food and growing food at home; and, finally, get a sense of general response to the proposed idea and its strategic direction:

I was first talking about this as a gimmick... and there were a few tech people who might have said, 'Yeah, I can see this working, I would buy this.' But then there are the people...the more serious, more grounded people, if you like. When we started talking about this as a kid's toy... an educational product, it was more specific. And for them, they saw more value in that. And suddenly I saw more value. I went away from this jovial, 'Oh, it's a lifestyle product, you don't really need it', to actually to respond to this key question: 'How can we develop our children's understanding of how to grow food?' This is... a strategic tool to help society address its problems. To help adults alleviate their concerns about how their kids are growing up and spending too much time staring at a glowing rectangle. [Tom, Designer, Food] 
The conversation quickly led to challenge some of the designer's most basic assumptions about the product and its core value proposition. He came to realise that refocusing the product on children means that 'it has more value, $[\ldots]$ more inherent value and more room to play' [ibid.] in that it opens up different markets (e.g. children, schools, other educational institutions etc.). Importantly, however, it also revealed the product's potential for addressing what is described vaguely as societal problems and hence more serious needs (as opposed to something 'jovial'). Early engagement with the potential target audience, as a frequently cited characteristic of design thinking, has opened up an interpretative space that allowed for the readjustment of the original idea. Design work does not come to an end with the completion of the product and formation of a new venture but it is a continuous process; a process that involves the reappraisal of the ends to be achieved and courses of action to be pursued in relation to the environment in which one is operating.

\section{Concluding remarks: The role of design reconsidered}

Design has been carved out here as a mode of inquiry, an epistemic practice through which actors make sense of particular subject matters and devise courses of action to address the problem in question. As a process of research and learning, design allows participants pursuing the development of new things (products, services, apps, platforms etc.) to experiment with ideas and cope with the inherent element of unknowability regarding its acceptance, not just in the market, but also within the growing network of actors who might have a stake in it.

Echoing the definitional ambiguity that characterises design research, design here holds different meanings for different people. The plurality of voices, apart from reflecting varying 
degrees of design literacy, underlines the unsettled and fragmented state of the discipline and the absence of what one may describe as 'accepted truths'. As the semantic field of design is demarcated by scores of local or descriptive (as opposed to formal) definitions, it is hardly surprising that the situated accounts of design are more nuanced than the dualism pervading the design thinking literature, i.e., the division between a narrow aesthetic view and allencompassing strategic view of design, may suggest (Verganti 2009). Although designers in the programme typically demonstrate a high level practical understanding and an intuitive ability to support the process, they often struggle to explain what one might call the first principles of their work, i.e., the fundamental concepts or assumptions that are guiding their actions. Reflections on design frequently escape into broader contexts, revealing an acute awareness of the professions' changing role, as is brought home in the following comment by one of the designers:

[Design] is a huge emerging market... where design consultancies will work with companies to consider their processes and the workings of their institution, to better their ability to respond to markets or to manage themselves. So I think applying a design process to all types of things is definitely a way forward. But also understanding that the design process is really just a method for finding ideas. [Gary, Designer, ICT]

Welcoming the expansion of design for the benefit of an increasingly diverse clientele (such as helping businesses to rethink their organisational practices), and acknowledging its role within different contexts, the designer still emphasises the importance of understanding what he sees as the basic function of a design: finding ideas. The design process, in turn, allows to organise this, bringing to bear the exploratory capacities of design. In a similar vein and lay terms, one of the non-designers describes his experience of design at the early stage of the 
project as 'the kicking of the idea around' [Greg, Entrepreneur, Rural Economies]. The willingness and trained ability of designers to see things differently are characteristic of their sense-making and constitutive of the profession's claims to its particular strengths. As one service designer comments:

I just think that [design thinking] is much more exploratory and much more, I guess, kind of open to looking at creative alternatives. Not just thinking about, 'Here's what we've always done or here's the accepted models and we need to basically work within them.' Just trying to think in a completely different way. I think design does bring that. [Lisa, Designer, Wellbeing]

The view being elaborated here is for a more holistic concept of design thinking that not only manifests 'a different way of thinking' but also 'a set of methods and tools to support you in thinking differently about challenges' [ibid.]. It offers methods of inquiry that allow for different ways of knowing, which 'take people out of perhaps their kind of standard approaches' [ibid.]. It is in this sense that the workshops, and by analogy design, work as an integrative discipline of understanding. It allows people to form communities of inquiry, subscribing to locally defined sets of principles, processes and methods (that may be articulated through specific rules of engagement), and to develop an understanding of purposeful exploration that shifts the focus from the organisation to 'the form of the final thing and how that is experienced' [ibid.]. Being embedded in such exploratory processes grants people what one participant described as 'creative freedom' [Jackie, Entrepreneur, Rural Economies]. Participants are allowed the time and space to inquire into a problematic situation and explore solutions that may be out of the ordinary. In fact, participants are 
actively pushed to go 'beyond the obvious', however that may be defined within a specific context.

The initiative has generated more than a dozen (seed-) funded projects with representation from all sectors covered. The place and role of design in each project varied and with it the processes and design expertise applied. As design is being re-assembled for increasingly diverse use cases, questions arise about the representation of design, especially given its pluralistic character not only in the way it is conceptualised but also, and in particular, in the way it is practiced. Such variations undermine the often unambiguous accounts of design that pervade the public discourse and nurture a curious quest for certainty that echoes the kind of conceptual stability pursued in the early years of design theorisation. Such early formulaic understanding of design never quite lost its appeal, as it seems, and with the growing interest in its transformative powers, the desire for a decontextualised, replicable version of the design process is strangely alive. In trying to appeal to business by appropriating and pursuing a Tayloristic view of the design process, i.e., turning design into a neatly defined manageable process with seemingly clear inputs and outputs (cf. Cross 2001, p. 51), the discipline is at risk of losing its distinctly indeterminate character.

Design works to overcome disciplinary divides and conceptual binaries (such as aesthetic versus strategic; user- versus producer-centred; linear versus circular) that afflict the pursuit of common ends and undermine understandings enacted through shared practice. Vital to the integrative function of design are locally established epistemic structures that allow for people with different frames of reference and exploratory approaches to settle on a shared path of inquiry. Design, in this sense, fulfils a brokering function that helps to align different ways of knowing along processes of shared exploration. As much as design emerged to 
remedy the breach between the scientific and aesthetic at the end of the nineteenth century (Flusser \& Cullars 1995, p. 51), it seems to enter the economy as a mediating device between different professional and functional disciplines. Determinative to the successful activation of design in business, however, is the presence of capable, multilingual ambassadors on the ground, able to fulfil such integrative and translational role.

Within a general framework of innovation, design can be seen as enabling the different processes constitutive of this: the production of knowledge, the transformation of knowledge into artefacts and the matching of the latter to specific demands and needs (Pavitt 2005). Presented is a view of design as an integrative discipline of understanding, grounded in the acceptance and actualisation of specific sets of principles, processes and methods that carry with them the attributes of what one might call a design ethos. That is, an approach to work that emphasises qualities such as collaboration, experimentation, iteration and practical relevance. In promoting testing and reasoning along the often winding path from problem finding to problem solving, from the conception of ideas to the formation of new entrepreneurial ventures, design supports activities of learning that help to cope with the inherent uncertainties that characterise the development of innovative goods. Importantly, designers are not idealised in the process as gifted individuals but embedded in a network of mutually influencing actors. The process reported on here in so far worked to connect separated systems of thinking and acting, allowing for an integrated understanding of the human condition within the artefactual world and an experience of design as 'an integral part of the stuff of life' (Walter Gropius (1937) as cited in Buchanan 1992, p. 2).

\section{Acknowledgements}


This research was funded by the Arts and Humanities Research Council (Grant number: $\mathrm{AH} / \mathrm{J} 005126 / 1)$. The text reflects the views of the authors and not the views of the funding body. We extend our thanks to the many participants who have committed themselves to this research.

\section{References}

Andrews, D. and C. Criscuolo (2013), 'Knowledge-based Capital, Innovation and Resource Allocation', OECD Economics Department Working Papers, No. 1046, OECD Publishing.

Brown, T. (2008), 'Design Thinking', Harvard Business Review, 86(6), 1-9.

Brown. T. (2009), Change by Design: How Design Thinking Transforms Organizations and Inspires Innovation, New York: Harper Collins.

Buchanan, R. (1992), 'Wicked Problems in Design Thinking', Design Issues, 8(2), 5-21.

Buchanan, R. (2001), 'Design Research and the New Learning', Design Issues, 17(4), 3-23.

Cross, N. (1982), 'Designerly Ways of Knowing', Design Studies, 3(4), 221-7.

Cross, N. (2001), 'Designerly Ways of Knowing: Design Discipline Versus Design Science', Design Issues, 17(3), 49-55.

Green, L., D. Cox and P. Bitard (2013), Innovation Policy and Design: Design As a Tool for Innovation. Innovation Policy Challenges for the 21st Century, New York: Routledge.

EPSRC (n.d.), Sandpits, accessed 4 April 2012 at

http://www.epsrc.ac.uk/funding/grants/network/ideas/Pages/whatisasandpit.aspx.

Flusser, V. and J. Cullars (1995), 'On the Word Design: An Etymological Essay', Design Issues, 11(3), 50-53. 
Gruber, M., N. de Leon, G. George and P. Thompson (2015), 'Managing by Design', Academy of Management Journal, 58(1), 1-7.

Hassi, L. and M. Laakso (2011), 'Design Thinking in the Management Discourse: Defining the Elements of the Concept', Proceedings of the 18th International Product Development Management Conference, 5-7 June 2011, Delft, The Netherlands.

Johansson, U. and J. Woodilla (2009), 'Towards an Epistemological Merger of Design Thinking, Strategy and Innovation', Proceedings of the 8th European Academy of Design Conference, 1-3 April 2009, Aberdeen, Scotland.

Jones, J.C. (1992), Design Methods, 2 ed. New York, Chichester: John Wiley \& Sons. Junginger, S. (2009), 'Parts and wholes: Places of design thinking in organizational life', Proceedings of the 8th European Academy of Design Conference, 1-3 April 2009, Aberdeen, Scotland.

Junginger, S. (2012), 'Design Concepts and Design Practices in Policy-Making and Public Management: New Challenges and New Opportunities for Policy-Makers and Public Managers', Proceedings of the RUC Sunrise Conference: Transforming Governance, Enhancing Innovation, 29-31 October 2012, Roskilde, Denmark.

Kimbell, L. (2011), 'Rethinking Design Thinking: Part I', Design and Culture, 3(3), 285-306. Kimbell, L. (2012), 'Rethinking Design Thinking: Part II', Design and Culture, 4(2), 129-148. OECD (2012), 'New Sources of Growth: Knowledge-Based Capital - Interim Project Findings', Meeting of the OECD Council at Ministerial Level, Paris, 23-24 May 2012, Paris: OECD Publishing.

Pavitt, K. (2005), 'Innovation Processes', in Jan Fagergerg, David C. Mowery and Richard R. Nelson (eds), The Oxford Handbook of Innovation, Oxford: Oxford University Press, pp. 86-114. 
Rittel, H. and M. Webber (1973), 'Dilemmas in a General Theory of Planning', Policy Sciences, 4(2), 155-169.

Sapsed, J. and A. Salter (2004), 'Postcards from the Edge: Local Communities, Global Programs and Boundary Objects', Organization Studies, 25(9), 1515-1534.

Schön, D.A. (1992), 'The Theory of Inquiry: Dewey's Legacy to Education', Curriculum Inquiry, 22(2), 119-139.

Simon, H.A. (1969), The Sciences of the Artificial, Cambridge, Massachusetts: MIT Press, 1996. Print.

The Scottish Government (2007), The Government Economic Strategy 2007. Edinburgh.

The Scottish Government (2011), The Government Economic Strategy 2011. Edinburgh.

Thomson, M. and T. Koskinen (2012), Design for Growth and Prosperity: Report and Recommendations of the European Design Leadership Board, Helsinki: DG Enterprise and Industry of the European Commission.

UK Department for Business, Innovation and Skills (2014), Innovation Report 2014, London.

Verganti, R. (2009), Design-driven Innovation: Changing the Rule of Competition by Radically Innovating What Things Mean, Boston, Massachusetts: Harvard Business Press.

Wallace, D.F. (2009), This is Water: Some Thoughts, Delivered on a Significant Occasion, about Living a Compassionate Life, New York: Little, Brown and Company.

Walters, H. (2011), 'Design Thinking Won’t Save You', blog post, 21 March, accessed 6 November 2015 at http://helenwalters.com/2011/03/21/design-thinking-wont-save-you. 